\title{
Investigation of the Effect of Confining Pressure on the Mechanics-Permeability Behavior of Mudstone under Triaxial Compression
}

\author{
Lu Shi $\mathbb{D}$, Zhijiao Zeng, Zhiming Fang, and Xiaochun Li \\ State Key Laboratory of Geomechanics and Geotechnical Engineering, Institute of Rock and Soil Mechanics, Chinese Academy \\ of Sciences, Wuhan 430071, China
}

Correspondence should be addressed to Lu Shi; shilu.whrsm@qq.com

Received 19 March 2019; Accepted 23 May 2019; Published 4 June 2019

Academic Editor: Agnes Mazot

Copyright ( 2019 Lu Shi et al. This is an open access article distributed under the Creative Commons Attribution License, which permits unrestricted use, distribution, and reproduction in any medium, provided the original work is properly cited.

\begin{abstract}
Injecting $\mathrm{CO}_{2}$ into a reservoir disturbs the geostress field, which leads to variations in the permeability of caprock and affects its sealing performance. In this paper, the evolution characteristics of the permeability of Yingcheng mudstone were experimentally studied during deviatoric compression under different confining pressures. As the confining pressure increased, the strength of the mudstone increased bilinearly, the angle between the fault and the maximum principle stress increased, and the fault became flatter. During compression, the permeability of mudstone first decreased and then increased and the turning point of the permeability was between the onset of dilatancy and the turning point of volumetric strain; when the fault formed, the permeability increased sharply and the fault-induced increment was reduced exponentially with increasing confining pressure. In addition, the mudstone transformed to the ductile failure mode when the effective confining pressure was greater than $35 \mathrm{MPa}$, which means that the permeability did not jump within a small strain. Finally, a practical strain-based model of permeability evolution that separately considers compaction and dilatancy was proposed, and the predicted permeability values were in good agreement with the experimental results. This study revealed the effect of confining pressure on permeability evolution during compression and can help evaluate the sealing ability of mudstone caprock.
\end{abstract}

\section{Introduction}

Mudstone, the most common material in sedimentary basins, has extremely low permeability and high capillary entry pressure [1], which means that geofluids take a very long time to saturate and pass through a mudstone formation [2]. Therefore, mudstone formations are an effective barrier to geofluid accumulation and play an important role in petroleum systems and in deep energy and waste disposals. Although not always the case, the permeability of mudstones in a well-compacted and undisturbed state is less than $1 \mu \mathrm{D}$ $\left(\approx 10^{-18} \mathrm{~m}^{2}\right)$ based on laboratory measurements of intact mudstone samples [3-9]; the reason for this result is that mudstone is rich in fine-grained and clay sediments and usually has a mean pore radius of less than $100 \mathrm{~nm}[4,10,11]$, which is more than several orders of magnitude smaller than that of coarser-grained rocks such as sandstone that retains geofluids [12, 13]. Since the clay grains are platy shaped, mudstone has higher compressibility than other sedimentary rocks and its permeability, which is related to porosity, decreases greatly with increasing diagenesis depth or consolidation pressure [14-18]. Therefore, many researchers have carried out experiments on the influence of effective hydrostatic pressure or consolidation pressure on mudstone permeability to understand the stress sensitivity of mudstone permeability [2, 19-21].

In $\mathrm{CO}_{2}$ capture and storage (CCS) projects, mudstone usually serves as the caprock formation to seal $\mathrm{CO}_{2}$ safely in the crust for a long time [22-25]; therefore, its permeability is the essential factor affecting its sealing performance. However, when $\mathrm{CO}_{2}$ is injected into deep saline aquifers or depleted hydrocarbon fields, the fluid pressure of the reservoirs will inevitably change, which influences the stress field of the caprock. Stress changes during injection may 
cause deformation and damage to the caprock and even result in failure of the caprock when the stress state approaches the failure envelope [9]. Since the pore structure of caprock can be altered due to these behaviors, its permeability will also change during $\mathrm{CO}_{2}$ injection, which can affect the sealing performance of the caprock. Therefore, a comprehensive understanding of the response of mudstone permeability to stress is crucial when accessing the leakage risk of CCS sites. However, reports on the evolution of mudstone permeability under general stress variations, such as conventional triaxial compression (CTC) with constant confining pressure, are very limited.

Hydrostatic or confined compression usually makes the mudstone more compact and less permeable. However, many CTC tests on sandstone [26-33], granite [34-36], limestone $[33,37,38]$, etc. have revealed that the permeability of the sample gradually increases until failure after the initial reduction during compression, and the formation of faults leads to a jump in the permeability magnitude; the variation in mudstone permeability shows the same trend during compression with a relatively low effective confining pressure $[28,39,40]$. For CCS projects, the caprock studied is usually at a depth of over $1 \mathrm{~km}$ below the ground and the lithostatic pressure is greater than $25 \mathrm{MPa}$ [19]. However, there is a severe lack of data concerning the permeability variation in mudstone corresponding to compression under a high confining pressure, which is the objective of this study. More importantly, to better understand the relationship between the permeability and the deformation of mudstone, experiments were carried out to measure permeability changes during deviatoric compression with different confining pressures. Therefore, the results of this paper are very helpful in assessing the leakage risk from $\mathrm{CO}_{2}$ injection sites.

\section{Specimen, Apparatus, and Experimental Procedure}

The brown mudstone cores for investigation were drilled in the Paleogene Formation at a depth of $30 \sim 40 \mathrm{~m}$ from Yingcheng, China. The mudstone belongs to the lower part of the Paleogene Gypsum-Salt Formation of the Yunying Sag in the northeast of the Jianghan Basin and has a diagenesis depth of more than $1500 \mathrm{~m}$. Therefore, the preconsolidation pressure should be greater than $30 \mathrm{MPa}$. The mudstone was composed of $14 \%$ feldspar, $23 \%$ quartz, $15 \%$ calcite, $3 \%$ hematite, $6 \%$ dolomite, $9.75 \%$ illite, $5.85 \%$ chlorite, and $23.4 \%$ montmorillonite. The skeleton particles of the mudstone were composed mainly of quartz, calcite, and feldspar, and the particles were cemented by clay minerals. Most of the mudstone composition, except for the clay minerals, was silt-sized particles. The pore radius distribution of the mudstone was unimodal, with the peak located at approximately $16 \mathrm{~nm}$, and pores with radii less than $100 \mathrm{~nm}$ accounted for more than $95 \%$. Moreover, the porosity of the mudstone is as high as $21.83 \%$.

We have already used the same cores to study the influence of the intermediate principal stress $\left(\sigma_{2}\right)$ on the permeability evolution during true triaxial compression [41]. Although this paper emphasizes the effect of confining

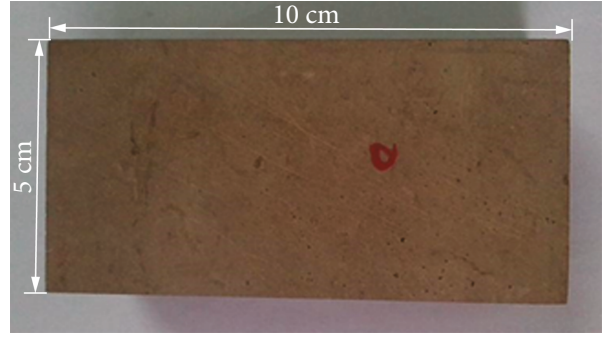

FIGURE 1: Cuboid specimen of mudstone with dimensions of $50 \times 50 \times 100 \mathrm{~mm}$.

pressure $\left(P_{c}\right)$ on the strain-permeability behavior of mudstone, which can be tested by a conventional triaxial apparatus with a cylindrical specimen, the true triaxial apparatus for rocks [41-45] at the Institute of Rock and Soil Mechanics, Chinese Academy of Sciences, which can exert three stresses independently, was still employed in this study because the specimen usually failed with a relatively flat fault parallel to $\sigma_{2}$ [42, 46-48]; the flow in the $\sigma_{2}$ direction can still be regarded as a one-dimensional flow. In contrast, the fault of the specimen in the CTC is not only very rough but also oblique to the flow direction $[40,49]$ and the fluid flow inside the specimen near or after failure cannot be approximated as a one-dimensional flow; therefore, the cores in this study were also processed into cuboid specimens of $5 \mathrm{~cm}$ square by $10 \mathrm{~cm}$ long (Figure 1 ) and the permeability in the $\sigma_{2}$ direction was monitored during deviatoric loading. The permeability of the mudstone was measured using the transient pulse method (TPM) [50-53] with nitrogen as the fluid medium. The apparatus and its reliability, the principles of TPM, and the experimental procedure were detailed in Shi et al. [41].

Six specimens (P4 to P9) were compressed at confining pressures of $8,15,22,30,40$, and $50 \mathrm{MPa}$ to study the influence of confining pressure on the permeability evolution and the corresponding mechanical behaviors of mudstone during compression. The deviatoric stress in the $\sigma_{2}$ direction for all specimens was $2 \mathrm{MPa}$, which is the minimum value for normal operation of the true triaxial apparatus. In addition, the pore pressure was maintained at $5 \mathrm{MPa}$. The specific loading process was as follows: first, pressures of $4 \mathrm{MPa}$ and $2 \mathrm{MPa}$ were provided to clamp the specimen assembly in the maximum principal stress $\left(\sigma_{1}\right)$ and $\sigma_{2}$ directions, respectively; then the confining pressure was raised to a predetermined value; the permeability measurement system was evacuated, and a pore pressure of $5 \mathrm{MPa}$ was exerted in sequence; finally, deviatoric compression in the direction was implemented. During the loading process of $\sigma_{1}$, the permeability of each specimen was measured approximately 9 times at different stress-strain states. The mudstone has obvious creep characteristics, and the specimen undergoes large deformation during permeability measurement, which takes over a half hour to complete; therefore, in the permeability measurement, strains, rather than stresses, were kept unchanged. Notice that the increasing $P_{\mathrm{c}}$ is consistent with the simultaneously increasing minimum principal stress 
TABLE 1: Strength, deformation parameters, and permeability of mudstone specimens.

\begin{tabular}{lccccccccccc}
\hline No. & $P_{\mathrm{c}}(\mathrm{MPa})$ & $E_{\mathrm{u}}(\mathrm{GPa})$ & $\sigma_{\mathrm{f}}(\mathrm{MPa})$ & $\sigma_{\mathrm{r}}(\mathrm{MPa})$ & $\epsilon_{1 \mathrm{f}}(\%)$ & $\epsilon_{3 \mathrm{f}}(\%)$ & $\epsilon_{\mathrm{d}}(\%)$ & $k_{2 \mathrm{a}}(\mu \mathrm{D})$ & $k_{2 \min }(\mu \mathrm{D})$ & $k_{2 \max }(\mu \mathrm{D})$ & $\frac{k_{2 \max }}{k_{2 \mathrm{a}}}$ \\
\hline P4 & 8 & 8.923 & 52.81 & 43.73 & 3.366 & -1.208 & 2.864 & 1.64 & 0.93 & 763.47 & 465 \\
P5 & 15 & 7.593 & 92.29 & 68.67 & 3.978 & -1.512 & 2.960 & 1.77 & 1.01 & 11.74 & 6.6 \\
P6 & 22 & 7.932 & 109.07 & 81.63 & 4.653 & -1.591 & 3.555 & 0.91 & 0.46 & 4.12 & 4.5 \\
P7 & 30 & 8.181 & 131.46 & 111.45 & 6.387 & -2.547 & 5.147 & 0.61 & 0.29 & 0.91 & 1.5 \\
P8 & 40 & 8.930 & 157.91 & $/$ & $/$ & $/$ & $>7.83$ & 0.51 & 0.24 & 0.66 & 1.3 \\
P9 & 50 & 9.719 & 187.52 & $/$ & $/$ & $/$ & $>7.99$ & 0.34 & 0.07 & 0.34 & 1 \\
\hline
\end{tabular}

$E_{\mathrm{u}}$ is the unloading modulus; $\sigma_{\mathrm{f}}$ is the strength; $\sigma_{\mathrm{r}}$ is the residual strength; $\epsilon_{1 \mathrm{f}}$ and $\epsilon_{3 \mathrm{f}}$ are the strains at the peaks in the $\sigma_{1}$ and $\sigma_{3}$ directions, respectively; $\epsilon_{\mathrm{d}}$ is the degree of ductility; $k_{2 \mathrm{a}}, k_{2 \min }$, and $k_{2 \max }$ are the initial, minimum, and maximum permeability values, respectively, in the $\sigma_{2}$ direction during deviatoric loading.

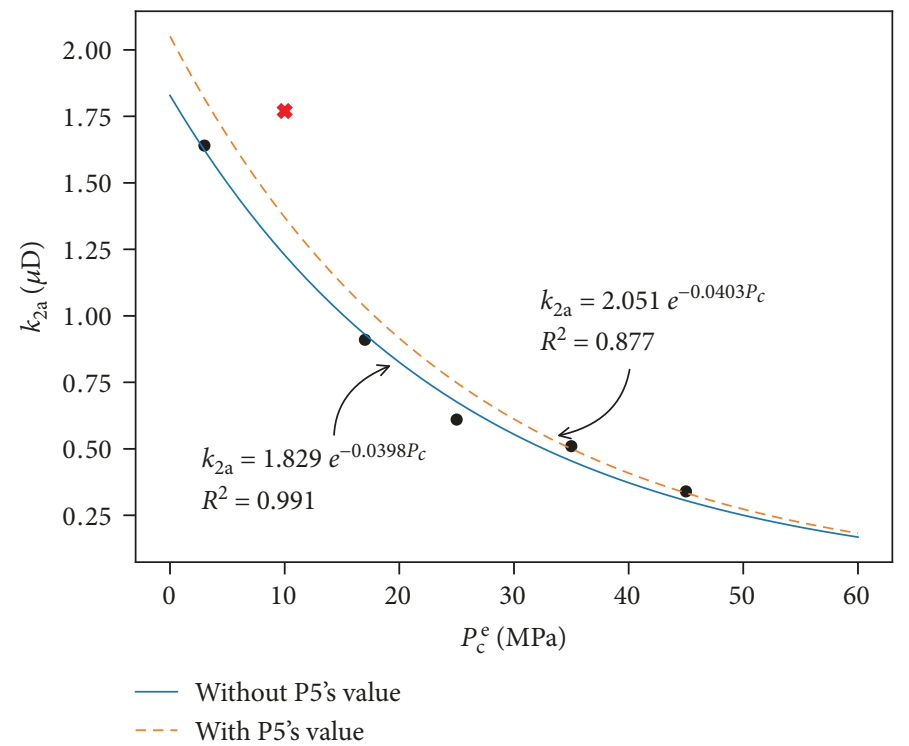

FIGURE 2: Variation in mudstone permeability with effective confining pressure under hydrostatic condition.

$\left(\sigma_{3}\right)$ and $\sigma_{2}$; therefore, the effect of $P_{c}$ is not equivalent to the influence of $\sigma_{3}$.

\section{Test Results and Interpretation}

The major test results related to the permeability and deformation behaviors of each specimen are summarized in Table 1. The deformation mechanisms of rocks under hydrostatic compression and deviatoric compression are significantly different. In addition, the specimen cannot be regard as a homogeneous body due to the formation of faults, which dramatically affects deformation behavior and permeability. Therefore, the influence of confining pressure on permeability and mechanical behavior will be described in three sections of hydrostatic compression and deviatoric compressions before and after the peak.

3.1. Hydrostatic Compression. We did not test the permeability at different hydrostatic pressures on a single specimen, but the effect of the confining pressure on permeability in this section can still be illustrated according to initial permeability $\left(k_{2 \mathrm{a}}\right)$ before the deviatoric loading of different specimens.
In general, the permeability of the mudstone decreases nonlinearly with confining pressure during hydrostatic compression and the power function [54] or exponential function [21, 55] was usually used to fit the relationship between effective confining pressure $\left(P_{c}^{e}\right)$ and permeability, where the superscript e represents effective stress. The results of fitting the $k_{2 \mathrm{a}}-P_{\mathrm{c}}^{\mathrm{e}}$ relationship using an exponential function $k_{2 \mathrm{a}}=k_{0} e^{-b P_{\mathrm{c}}^{\mathrm{e}}}$ are shown in Figure 2; here, $k_{0}$ and $b$ are two parameters used to represent the permeability at $P_{\mathrm{c}}^{\mathrm{e}}=0$ and the sensitivity of permeability variation to confining pressure. The $R$-squared value for the exponential function with $k_{2 \mathrm{a}}=2.051 \mu \mathrm{D}$ and $b=-0.0403 \mathrm{MPa}^{-1}$ used to fit the values of all six specimens was 0.877 . When the $k_{2 \mathrm{a}}$ of specimen P5 that was greater than that of specimen P4 under higher confining pressure was removed, the goodness of fit was improved to 0.991; however, the parameters from the fit varied very little, i.e., $k_{2 \mathrm{a}}=1.829 \mu \mathrm{D}$ and $b=-0.0398 \mathrm{MPa}^{-1}$.

Compared with the reported permeability of mudstones $[2,21,40,54]$, the permeability under hydrostatic compression has two characteristics: $(1)$ the permeability $k_{0}(\approx 2 \mu \mathrm{D})$ is low and (2) the permeability is less sensitive to changes 


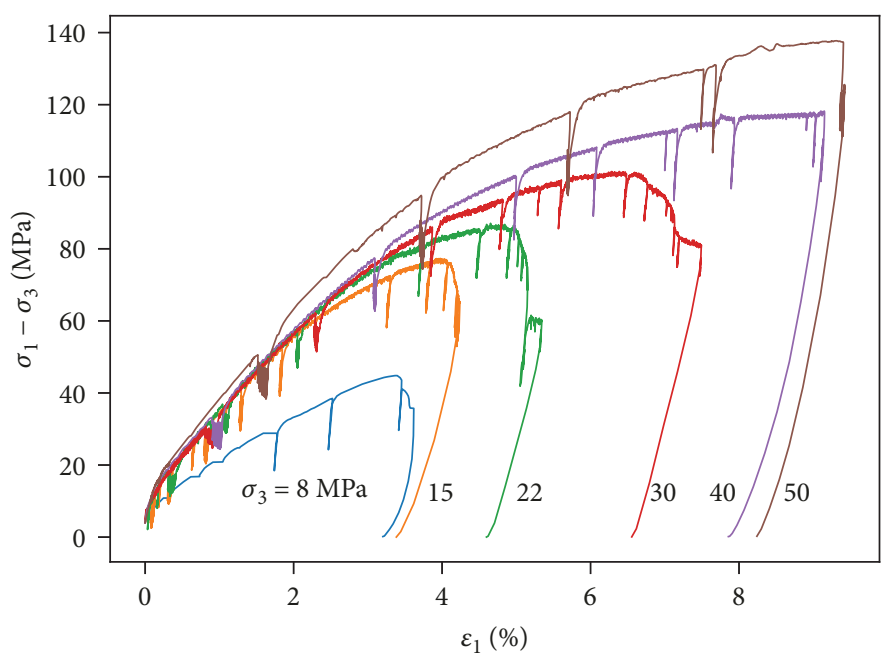

Figure 3: Curves of deviatoric stress $\sigma_{1}-\sigma_{3}$ vs. strain $\epsilon_{1}$ for different confining pressure.

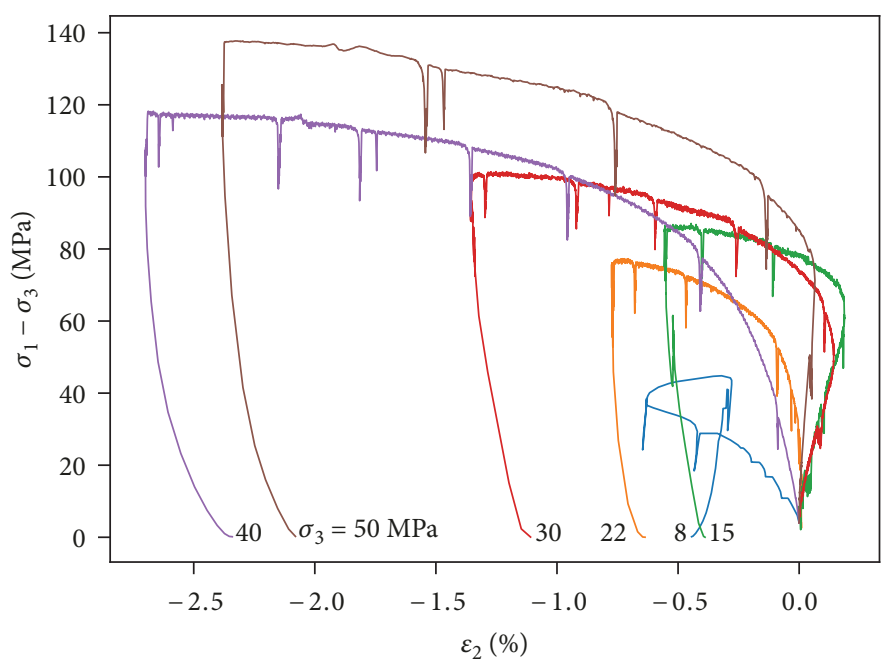

FIgURE 4: Curves of deviatoric stress $\sigma_{1}-\sigma_{3}$ vs. strain $\epsilon_{2}$ for different confining pressure.

in confining pressure. The permeability of mudstone under a certain hydrostatic pressure is closely related to the preconsolidation pressure of the mudstone; experiments revealed that mudstone permeability during pressurized steps is significantly higher than that during depressurized steps $[2,21,40]$, which is because the closure of the microcracks and pore throat and the rearrangement of the platy clay grains are irreversible. Therefore, there may be two reasons for the relatively low value of $k_{0}$. First, the preconsolidation pressure is high and the near-surface coring without significant stress release did not cause the formation of microcracks and damages in the samples. Second, the confining pressure was applied prior to the pore pressure, which means that the effective hydrostatic pressure first increased and then decreased; thus, permeability evolution in the low $P_{c}^{e}$ section, where the permeability drops sharply with increasing $P_{\mathrm{c}}^{\mathrm{e}}$, may not be captured. Moreover, when $P_{\mathrm{c}}^{\mathrm{e}}$ increased from $3 \mathrm{MPa}(\mathrm{P} 4)$ to $45 \mathrm{MPa}$ (P9), the permeability only decreased by approximately 5 times and the sensitivity of the mudstone permeability to $P_{\mathrm{c}}^{\mathrm{e}}$ is comparable to those of the mudstones reported by McKernan et al. [2], Zeng et al. [21], and Zhang [40] in depressurized steps.

3.2. Deviatoric Compression before the Peak. After applying the confining pressure, the mudstone specimens were deviatorically loaded while permeability was monitored. Figures 3-5 show the stress-strain relationship of Yingcheng mudstone under different confining pressures in the $\sigma_{1}, \sigma_{2}$, and $\sigma_{3}$ directions, respectively. Here, $\epsilon_{1}, \epsilon_{2}$, and $\epsilon_{3}$ represent the strains in the $\sigma_{1}, \sigma_{2}$, and $\sigma_{3}$ directions, respectively. The strains in the deviatoric loading stage start from zero, and those induced by hydrostatic compression were omitted. From the stress-strain curves, the permeability measurement points, where significant stress relaxation occurs, can be clearly identified. Notice that stress is constant during the first three permeability measurements of specimen P4. 


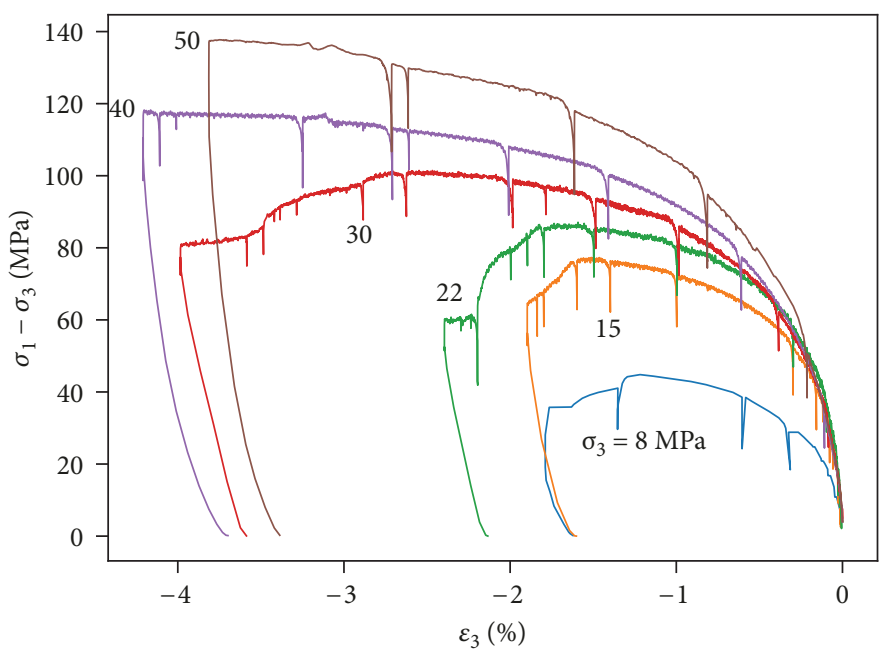

FIgURE 5: Curves of deviatoric stress $\sigma_{1}-\sigma_{3}$ vs. strain $\epsilon_{3}$ for different confining pressure.

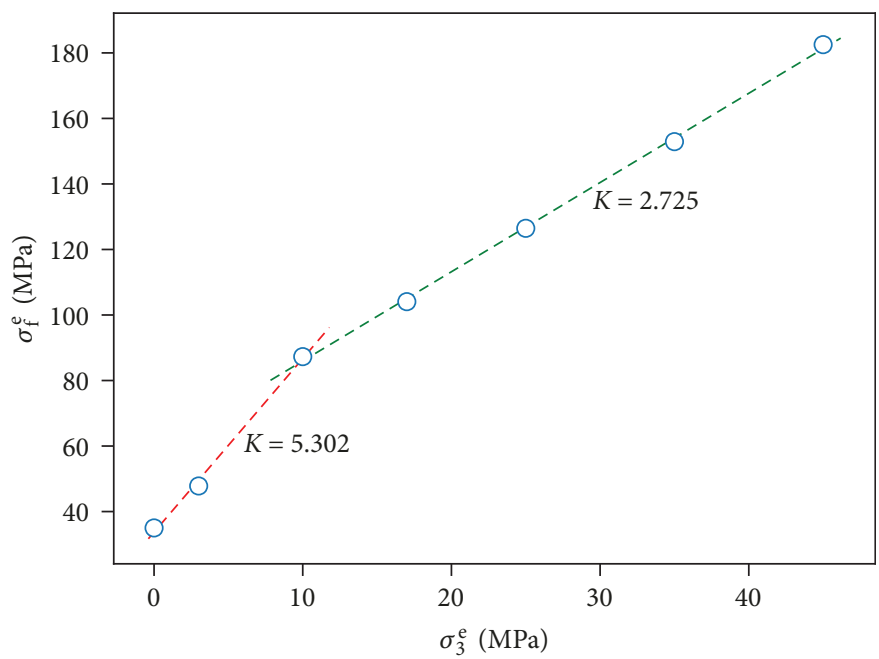

FIGURE 6: Yingcheng mudstone strength as a function of confining pressure.

3.2.1. Strength and Strains at the Peak. As shown in Figure 6, the failure strength $\sigma_{\mathrm{f}}$ of the specimen increased with the confining pressure. Note that the uniaxial compressive strength $\sigma_{c}$ of the mudstone that was tested using a cylindrical specimen $(\Phi 50 \times 100 \mathrm{~mm})$ is $35 \mathrm{MPa}$. Moreover, due to the limitation of the strain range $(9 \%)$ in the $\sigma_{1}$ direction, the failure of specimens P8 and P9 did not occur and their strengths were approximated. The variational trend of the strength can be represented by a bilinear model with slope $K$ equal to 5.302 and 2.725 at lower and higher confining pressures, respectively. That is, the sensitivity of strength to confining pressure with lower $P_{\mathrm{c}}$ is stronger than that with higher $P_{c}$, which is consistent with the results of other researchers [56,57], because the low confining pressure does not induce the closure of all microcracks before triaxial loading and the remaining microcracks cause a decrease in the strength of the specimen. If the $\sigma_{\mathrm{f}}-P_{\mathrm{c}}$ relationship is piecewise fitted by the Mohr-Coulomb criterion, the friction angles $\phi$ of the low- and high- $P_{\mathrm{c}}$ zones are approximately $43^{\circ}$ and $28^{\circ}$, respectively, and the corresponding shear failure angles oblique to the $\sigma_{3}$ direction are $66.5^{\circ}$ and $59^{\circ}$.

With the increase in $P_{c}$, the corresponding strain in each direction increased when the mudstone specimen reached its peak. When $P_{\mathrm{c}}$ exceeds $30 \mathrm{MPa}$, the increase became very significant due to the brittle-ductile transition of the mudstone. The ductility of the specimen can be quantified by the degree of ductility $\epsilon_{\mathrm{d}}$, which is defined as follows [58]:

$$
\epsilon_{\mathrm{d}}=\epsilon_{1 \mathrm{f}}-\frac{\left(\sigma_{1}-\sigma_{3}\right)_{\mathrm{f}}}{E_{\mathrm{u}}},
$$

where the subscript $\mathrm{f}$ represents the quantities at failure and $E_{\mathrm{u}}$ is the unloading modulus. In fact, $\epsilon_{\mathrm{d}}$ is the permanent strain in the $\sigma_{1}$ direction. From the data of $\epsilon_{\mathrm{d}}$ in Table 1, it can be concluded that the ductility of the mudstone increases remarkably with increasing confining pressure. The failure mode of specimens P4 and P5 can be classified as brittle 


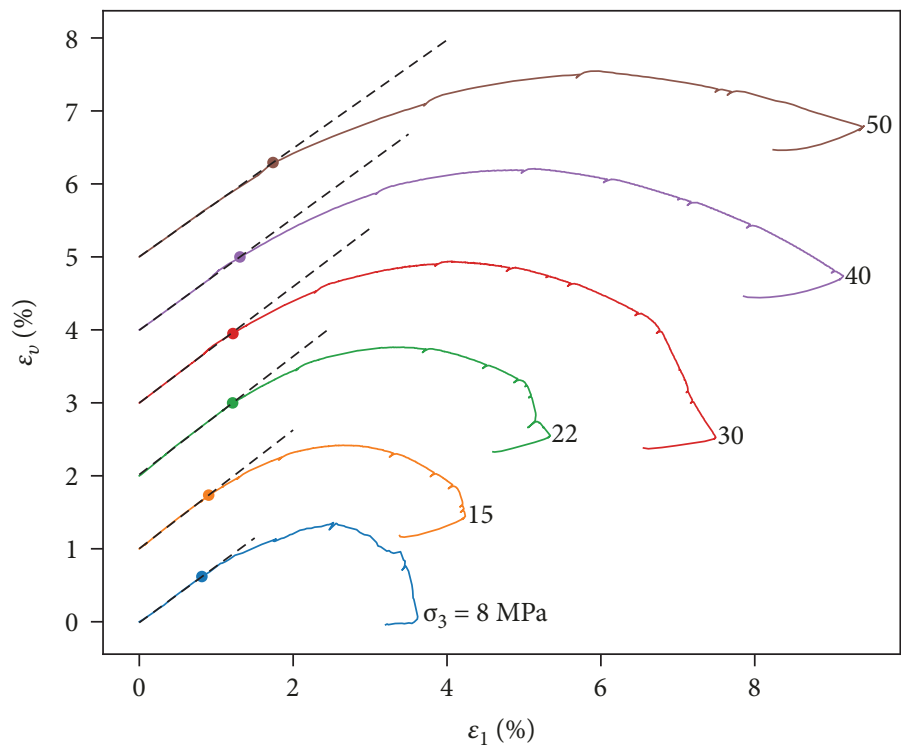

FIGURE 7: Volumetric strain as functions of strain $\epsilon_{1}$. The numbers for each curve are the confining pressure in MPa. For a clearer illustration, the curves at $15,22,30,40$, and $50 \mathrm{MPa}$ are translated by $1,2,3,4$, and 5 along the longitudinal axis, respectively.

failure $\left(\epsilon_{\mathrm{d}}<3 \%\right)$, and the failure mode of P6 is semibrittle, with $\epsilon_{\mathrm{d}}$ in the range from $3 \%$ to $5 \%$. The failure mode of P7 to P9 is ductile, with $\epsilon_{\mathrm{d}}$ greater than $5 \%$. Obviously, the mudstone has completed the brittle-ductile transition when $P_{\mathrm{c}}^{\mathrm{e}}$ has increased to $25 \mathrm{MPa}$. The high ductility of the mudstone helps maintain its sealing performance because the large deformation of caprock causes a decrease in the fluid pressure in the reservoir. In addition, ductile deformation does not bring about new seepage channels as brittle deformation does; therefore, it has little effect on permeability.

\subsubsection{Stress-Strain Behavior and Permeability Evolution.}

Unlike the stress-strain curve of hard rock, mudstone does not have a distinct linear elastic section at the beginning of loading; therefore, the yield point on each stress-strain curve is difficult to determine. The irreversible deformation induced by consolidation is always accompanied by compression, including hydrostatic precompaction [21, 33], before deviatoric loading. However, the onset of plastic deformation induced by the initialization, opening, and propagation of microcracks can be determined using the curve of $\epsilon_{1}$ against volumetric strain $\epsilon_{\mathrm{v}}$, which has a distinct linear section, as shown in Figure 7. The latter deformation is directly related to the dilatancy of the specimen, and a larger confining pressure delays the onset of dilatation, where deviatoric stress is approximately 45 to $50 \%$ of the peak. Another characteristic point is the turning point at which the specimen volume changes from compressive to dilatate, and the deviatoric stress at this point is approximately 80 to $85 \%$ of the peak. Notably, strains $\epsilon_{1}$ and $\epsilon_{2}$ were obtained by measuring the relative displacements of one side of the end spacers in the $\sigma_{1}$ and $\sigma_{3}$ directions, and the spacers were adjusted due to specimen preparation error, which brought a certain deviation to the measurement of these two strains under low load compression. In addition, the specimens were ground manually to avoid exposure to water; therefore, the preparation precision was relatively low and the $\epsilon_{2}$ may be measured inaccurately under extremely low deviatoric stress $(2 \mathrm{MPa})$ in the $\sigma_{2}$ direction.

The two points of the onset of dilatancy and the turn of volumetric strain can divide the prepeak deformation into three stages, which will be introduced in conjunction with the relative changes in the permeability (Figure 8) as follows:

(1) Nondilatant Stage. Before the stress of the specimen reaches the onset of dilatancy, the sizes of the pores and throats decrease and the original microcracks close under initial deviatoric loading, resulting in a decline in mudstone permeability. The magnitude of the decline is directly related to the degree of compaction in hydrostatic compression and therefore decreases with increasing confining pressure

(2) Gentle-Dilatant Stage. Further increasing the stress after reaching the onset of dilation results in the initialization, reopening, and propagation of microcracks, which undoubtedly increases the permeability of the specimen. However, when the stress has not yet reached the turning point of $\epsilon_{\mathrm{v}}$, the microcracks are still independent and do not fully connect with their neighbors to form an effective pathway. Moreover, the compaction process continues. Therefore, the permeability decreases first and then increases and the variation amplitude is relatively small. That is, the turning point of $k_{2}$ is located between the onset point of dilatancy and the turning point of $\epsilon_{\mathrm{v}}$

(3) Accelerated-Dilatant Stage. When the deviatoric stress exceeds the turning point of $\epsilon_{\mathrm{v}}$, the microcracks grow much faster and coalesce with neighbors to form macrofractures with further loading. Therefore, the increase in permeability in this stage is noticeable. The ratios of the permeability at the peak 


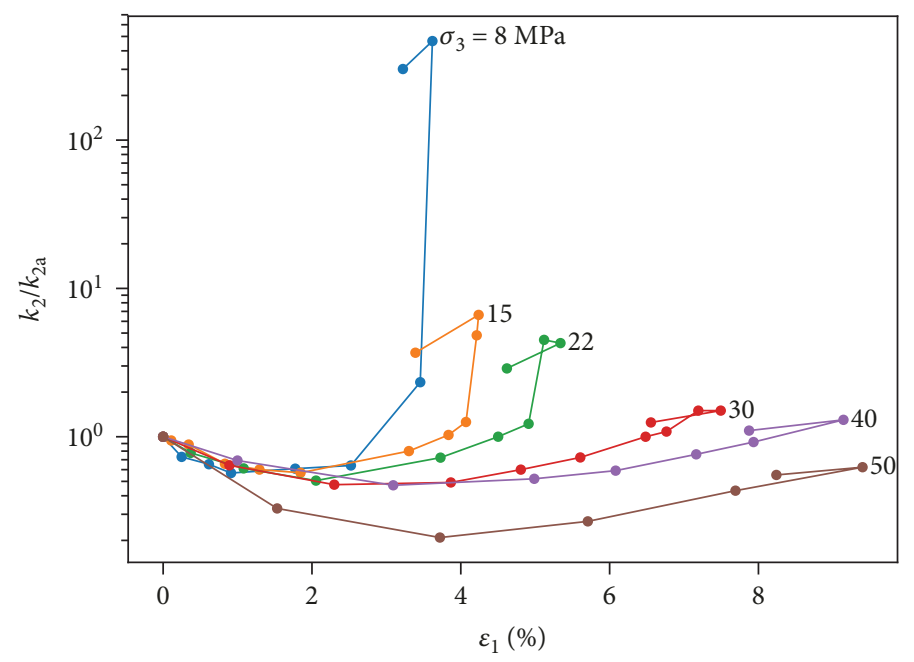

FIgURE 8: Relative change in permeability as functions of strain $\epsilon_{1}$ at different confining pressures.

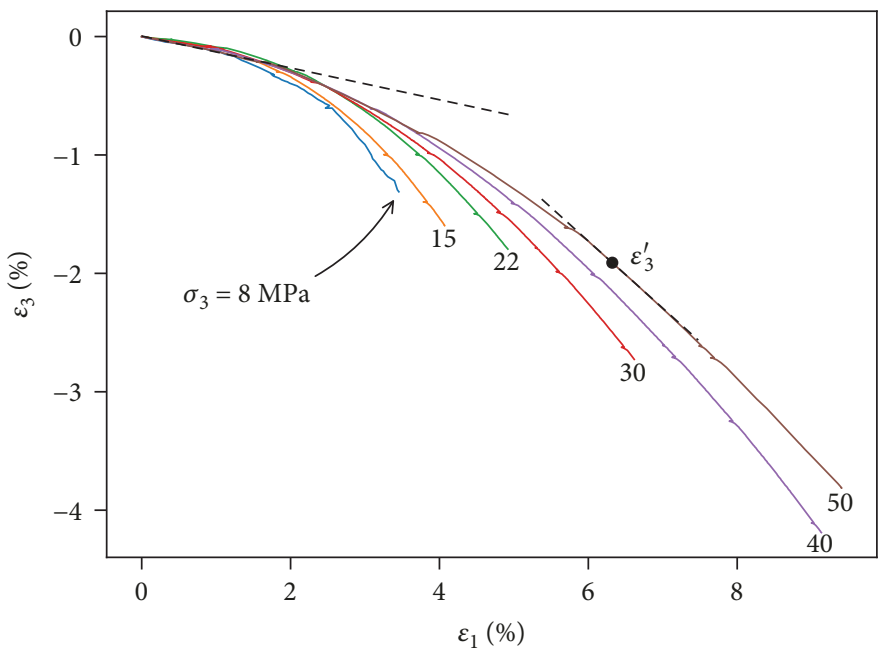

Figure 9: Strain $\epsilon_{3}$ as function of strain $\epsilon_{1}$ for different confining pressures together with the calculation of tangent Poisson's ratio.

to $k_{2 \mathrm{a}}$ of the six specimens are $2.33,1.26,1.22,1.00$, 1.30 , and 0.62 , respectively, which means that, in general, the increment in permeability in this stage is negatively correlated with the confining pressure

It can be concluded that the evolution of mudstone permeability during deviatoric loading is the result of a combination of compaction and dilatation and is dependent on the confining pressure.

When the specimens are unloaded, the volumetric strain of the specimens will decrease, mainly because the openings of the cracks became smaller, which leads to the decrease in mudstone permeability. After complete unloading of deviatoric stress, the reduction in permeability is negatively correlated with confining pressure: the corresponding permeability decreases of specimens P5 to P9 are $44 \%, 32 \%$, $17 \%, 15 \%$, and $11 \%$, respectively.

3.2.3. Prediction of Permeability Variation. Many models based on the power law or exponential law have been proposed to predict the permeability evolution during deviatoric compression in terms of stress and damage [41, 49, 59-61]. These models have been experimentally proven to have good predictive ability under hydrostatic compression but poor prediction ability under deviatoric compression [41, 49]. As mentioned above, compaction and dilatancy are two coupled processes that increase and decrease permeability, respectively. Therefore, Shi et al. [41] proposed a permeability-strain relationship that separately considers the contribution of compaction and dilatancy to permeability without using the indirect variable of damage. However, the model is not appropriate for applications where plastic deformation is large because the dilatant deformation weight $r_{\mathrm{d}}$ and predicted permeability are still increasing with deformation such as the rearrangement of clay grains, which can cause a decrease in permeability.

Figure 9 shows that $\epsilon_{3}$ at the peak increases remarkably with increasing confining pressure. In contrast, tangent Poisson's ratio $v$, defined as the magnitude of the slope of a tangent to the curve of $\epsilon_{3}$ versus $\epsilon_{1}$, decreases slightly with 


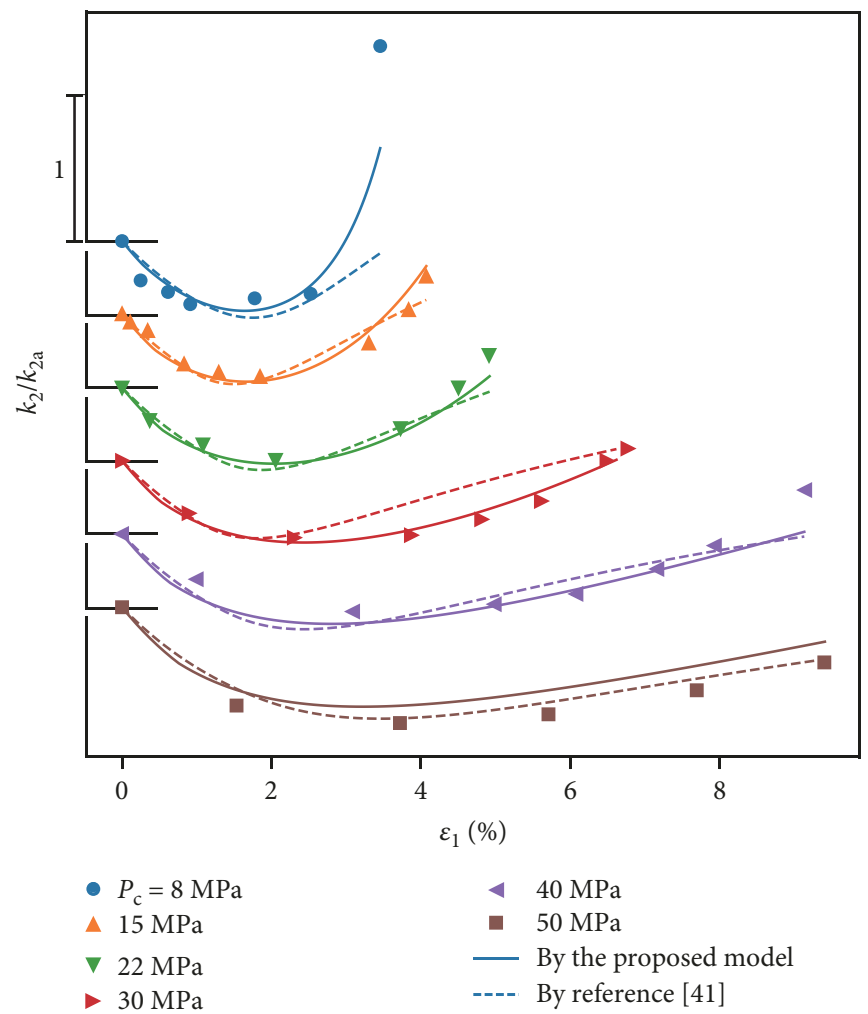

FIGURE 10: Comparison between the permeability obtained by model prediction (curve) and the testing results (mark). Note that the ordinate value of the starting point of each data set is 1 .

increasing confining pressure, which is consistent with the variation in the relative change in the permeability at failure with confining pressure (Figure 8). Therefore, this study attempts to employ the tangent Poisson's ratio to reflect the effect of dilatancy on the permeability, and the permeability evolution can be written as follows:

$$
\frac{k_{2}}{k_{2 \mathrm{a}}}=e^{-\alpha \epsilon_{1}}+e^{\beta\left(v-v_{0}\right)}-1,
$$

where $v_{0}$ is the initial tangent Poisson's ratio at the nondilatant section and $\alpha$ and $\beta$ are parameters that are set to 0.6372 and 0.9702 , respectively, by fitting the testing results with an $R$-squared value of 0.89 . For comparison, the permeability evolution is also fitted by our previously proposed model [41] and the two parameters and the $R$-squared value are $0.5314,2.182$, and 0.81 , respectively. The comparison of permeability values from the model prediction and the experiments plotted in Figure 10 shows that the proposed model can describe the permeability-strain relationship well before failure. Note that the permeability of specimen P4 at the peak does not contribute to the fit because strain localization has already started. Obviously, the prediction results of the model proposed in the study are superior to those by the model in Reference [41]. Moreover, the combination of permeability evolution functions under hydrostatic and deviatoric compressions can be easily applied in practical problems.
The permeability evolution after the peak, which is dominated by the formation and slippage of the fault, is not within the prediction range of the above model. Although the model can better match the permeability data of Yingcheng mudstone, it is based on experience and lacks theoretical background; therefore, the model needs further experimental verification.

3.2.4. Effect of Confining Pressure on Deformation Mechanism and Permeability Evolution. Mudstone is an extremely finegrained sediment with very small pores. The pore throat is smaller than the pore, and its aspect ratio, defined as the ratio of the breadth to the length of the section of the throat, is very small as a result of the platy nature of clay minerals [10]. When compressed, the narrow throats of mudstone are closed as easily as plate-shaped microcracks [54, 62]; many published data have shown that compaction-induced permeability reduction in mudstone is more sensitive than that in sandstone $[41,55,63]$.

The pressure that induces grain crushing is negatively correlated with grain size; thus, for mudstone with very fine grains $[27,64]$, grain crushing is less likely to occur within the studied pressure range. Therefore, there are two main types of plastic deformation of mudstone under deviatoric compression: pore compression and microcrack evolution. The entire loading process is accompanied by these two deformations. Undoubtedly, the latter increases the permeability, while the former reduces the permeability.

At the initial stage of deviatoric loading, pore compression and microcrack closure make the secant modulus 


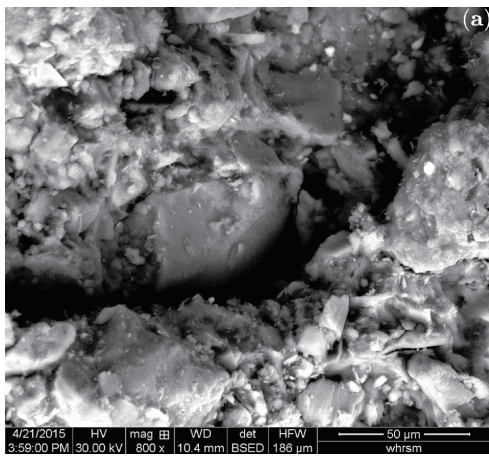

(a)

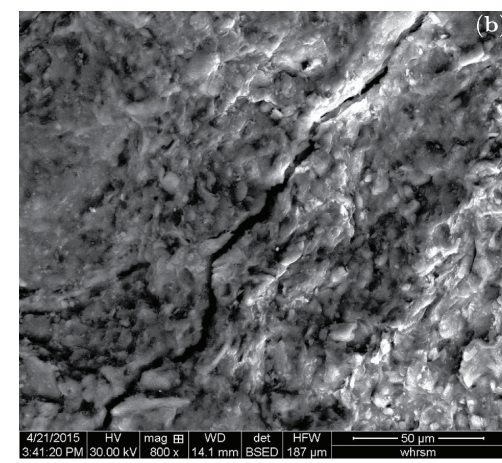

(b)

FIGURE 11: SEM photomicrographs of specimens after compressive tests: (a) specimen P5 under a confining pressure of $15 \mathrm{MPa}$; (b) specimen P9 under a confining pressure of $50 \mathrm{MPa}$.

(approximately 2.15 to $3.15 \mathrm{GPa}$ ) of the mudstone significantly lower than the unloading modulus. As the confining pressure increases, more pore and microcrack compressions occur during the exertion of the confining pressure; therefore, the irreversible strain in this stage decreases and the secant modulus increases slightly with the increase in the confining pressure. The rate of change of the permeability with $\epsilon_{1}$ is negatively correlated with the secant modulus of this stage, which can be illustrated by the highest rate of permeability change of specimen P4 (Figure 8 ), which has the lowest secant modulus $(2.15 \mathrm{GPa})$.

The strength of the mudstone is determined mainly by the evolution of microcracks. When the coalescence of growing microcracks progresses to a certain extent during deviatoric loading, the strain begins to localize, at which point the specimen begins to lose its load-carrying capacity. However, according to micromechanical theory, confining pressure can make the growth of microcracks more difficult $[65,66]$, which improves the specimen strength.

Mudstone is highly compressible because it is rich in platy clay particles whose microstructures vary from a card or book house structure to a perfect stack with considerable porosity loss. Therefore, crack propagation under higher confining pressures requires a greater deviatoric stress, leading to grain rearrangement and significant deformation.

Figure 11 illustrates two SEM photomicrographs (magnification 800) of specimens P5 and P9 after compressive testing, and their vertical and horizontal directions are coincident with the $\sigma_{1}$ and $\sigma_{3}$ directions, respectively. A large number of angular silt and sand grains $(>10 \mu \mathrm{m})$ can be observed in Figure 11(a), and these silt grains are in close proximity to each other. Pores larger than $5 \mu \mathrm{m}$ are visible everywhere, but the channels connecting them are either invisible or very narrow. In addition, the grains are randomly arranged and a very uneven crack with an average aperture of $25 \mu \mathrm{m}$ can be observed. The situation of specimen P9 under a high confining pressure in Figure 11(b) is almost opposite to that of specimen P5; namely, the grains are arranged in an orderly and compact manner, the slit grains are floating on the clay matrix, and a flat and closed crack can be found in line with the grain-arranged direction, which is oblique to the $\sigma_{1}$ direction. Regarding pores and cracks, the permeabil- ity of specimen P9 is obviously much lower than that of specimen $\mathrm{P} 5$, which verifies the microscopic mechanism explanation of the influence of confining pressure on the deformation and permeability of mudstone. Moreover, $k_{2 \mathrm{a}}$ of specimen P5 is relatively high possibly due to the high content of silt and sand grains.

3.3. Deviatoric Compression after the Peak. When deviatoric compression exceeded the peak, the load-carrying capacity of the specimen dropped sharply with the formation of the fault. In addition, the residual strength $\sigma_{\mathrm{r}}$ of the mudstone, which is directly related to the friction of the fault, increases with increasing confining pressure. Although the deviatoric stress in the $\sigma_{2}$ direction is very low, the specimen still failed with a flat fault parallel to the $\sigma_{2}$ direction, as in the normal true triaxial test, as shown in Figure 12. As $\sigma_{3}$ increases from 8 to $30 \mathrm{MPa}$, the angle between the failure surface and the $\sigma_{2}$ direction decreases gradually from $76^{\circ}$ to $61^{\circ}$. The failure angles of specimens $\mathrm{P} 5$ and $\mathrm{P} 7$, whose confining pressures are in the middle of the low $-P_{c}$ and high- $P_{c}$ regions, respectively, are close to the predicted failure angles of the Mohr-Coulomb criterion mentioned in Section 3.2.1. There is no fault on specimens P8 and P9 because failure has not occurred due to their high ductility. The fault is generated by the propagation and coalescence of a large number of microcracks. With increasing $\sigma_{1}$, the microcracks parallel to $\sigma_{1}$ grow in the form of axis split, while those that are oblique to $\sigma_{1}$ are more prone to shear propagation. The numbers of microcracks with split and shear growth are inversely related; i.e., the confining pressure can inhibit a splitting of microcracks. Therefore, when the number of shear propagation microcracks increases with increasing confining pressure, the fault is gentler when the $\sigma_{1}$ direction is vertical. In addition, the increased splitting failure of microcracks makes the fault rougher, which can be verified by the comparison of the faults of specimens P4 and P7. In general, the failure and aforementioned deformation are related to microcrack evolution.

In this compression section, the formation of fault results in a shape increase in permeability. At a low confining pressure of $8 \mathrm{MPa}$, the permeability is increased by two to three orders of magnitude. As the confining pressure increases 


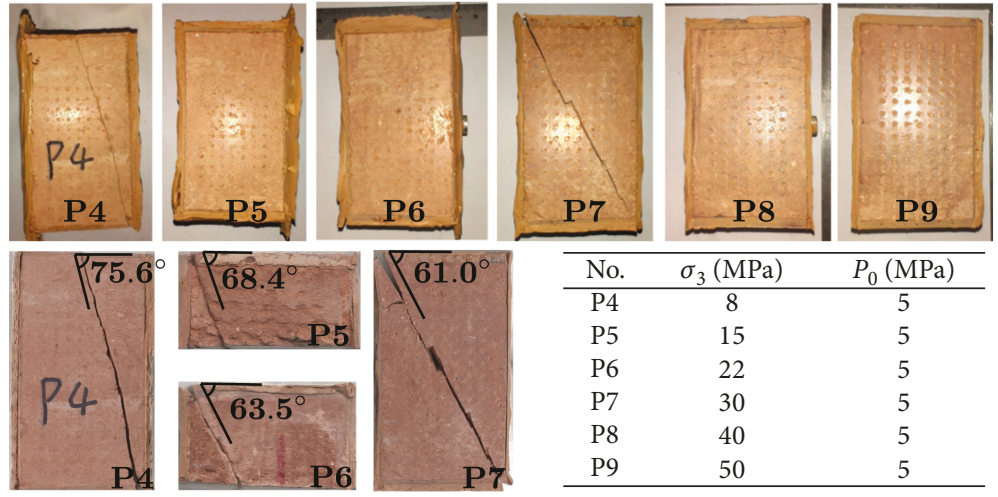

FIGURE 12: Failure pattern of specimens under different confining pressures. Note that the photos in the first row were taken after the test was completed in 2015. However, the faults of specimens P5 and P6 cannot be observed due to the tight compaction. Therefore, recent photos of the specimen are included in the second row. Most of specimens P5 and P6 were cut for analysis of mineral composition, porosity, and microstructure; specimens P8 and P9 were lost. The change in color is due to the loss of water from limonite to hematite.

from 15 to $30 \mathrm{MPa}$, the multitude of increases in the permeability relative to $k_{2 \mathrm{a}}$ decreases from 6.6 to 1.5 . Therefore, at a higher confining pressure, $\sigma_{3}>30 \mathrm{MPa}$ and the permeability does not change much with the formation of the fault. After the fault is sufficiently developed, deformation and permeability evolution are dominated by fault slippage.

Since the fault plane is parallel to the flow direction, the one-dimensional flow assumption after failure is still valid. Therefore, based on a sudden increase in permeability, the permeability of the local fault zone $k_{\mathrm{f}}$ can be estimated according to Figure 13. It is assumed here that (1) the fault is a shear zone with a certain width $D_{\mathrm{f}},(2)$ the shear zone is homogeneous, and (3) the permeability of the bulk $k_{\mathrm{b}}$ is the permeability at the peak and remains unchanged after failure. Therefore, $k_{\mathrm{f}}$ is given by $k_{\mathrm{f}}=\left(\Delta k_{\mathrm{b}} A\right) / A_{\mathrm{f}}$, where $A=L W$ is the cross-sectional area of the specimen and $A_{\mathrm{f}}=D_{\mathrm{f}} L \sec \theta_{\mathrm{f}}$ is the cross-sectional area of the fault zone. With the width of the fault zone set to $2 \mathrm{~mm}$ according to the results of Uehara and Takahashi [39], the local permeability $k_{\mathrm{f}}$ of specimens P4 to P7 is approximately $18.6 \mathrm{mD}, 224.7 \mu \mathrm{D}$, $68.1 \mu \mathrm{D}$, and $5.7 \mu \mathrm{D}$, respectively. Thus, the local permeability of the fault decreases exponentially with increasing confining pressure.

\section{Discussion}

In the CCS projects, $\mathrm{CO}_{2}$ is structurally trapped within deep geological formations over long periods of time $\left(10^{3}-10^{4}\right.$ years). Therefore, low permeability is a prerequisite for the effectiveness of the caprock. Low permeability means that it takes a long time for $\mathrm{CO}_{2}$ to penetrate the caprock and that the capillary pressure of the caprock is very high. Actually, permeability is a comprehensive representation of the rock pore-crack structure characteristics. Laboratory tests on 141 samples from different tectonic units of South China have shown that the relationship between capillary pressure and permeability can be expressed by a pow function with a negative exponent [67]. Chen et al. [68] pointed out that effective caprock in petroleum engineering

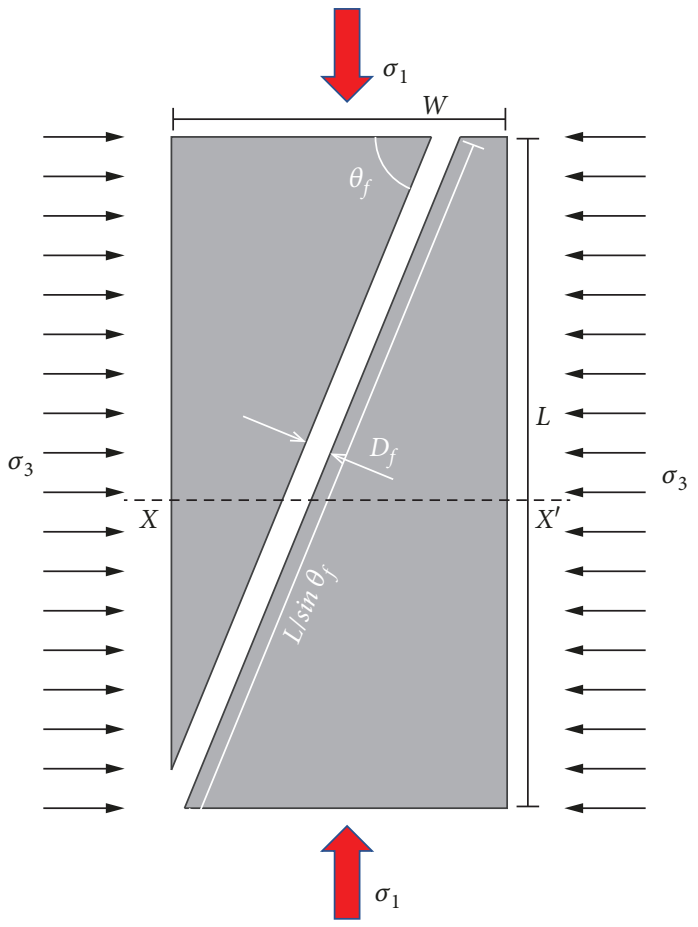

FIGURE 13: Schematic illustration of fault-contained cross-section perpendicular to the $\sigma_{2}$ direction.

should have a permeability of no more than $5 \times 10^{-19} \mathrm{~m}^{2}$ (approximately $0.5 \mu \mathrm{D}$ ).

In the field of petroleum engineering, the evaluation of caprock sealing properties helps locate oil-gas accumulations but the evolution of caprock sealability after exploitation is less of a concern. After $\mathrm{CO}_{2}$ is injected into the reservoir, the fluid pressure of the reservoir is significantly increased and the pressure increment is gradually attenuated from the injection well to other areas [69]. The reduction of effective stress in the reservoir will inevitably lead to uneven uplift of the overburden [70] and deformation in the caprock. From the above study, the permeability of mudstone caprock can be markedly increased by more than 5 times without failure, 
which cannot be neglected in the evaluation of caprock sealing performance; even for ductile deformed specimens $\mathrm{P} 8$ and $\mathrm{P} 9$, dilatancy occurred under deviatoric compression. In addition, the brittle-ductile property of caprock is considered to be the key factor controlling the integrity of the caprock, as brittle caprock is more susceptible to cracking after the uplift of the formation $[1,71]$. However, it can be inferred that, if the effective confining pressure exceeds $25 \mathrm{MPa}$, the increase in permeability of Yingcheng mudstone due to failure is insignificant.

In short, it is not enough to evaluate the sealing of the caprock of CCS simply by using indicators such as the overconsolidation ratio, density, and brittleness index, and special attention should be paid to the dynamic evolution of sealability after injection of $\mathrm{CO}_{2}$. Therefore, we should study the mechanical and permeability properties of caprock to obtain the constitutive equation and permeability evolution equation of caprock, establish a numerical model, and evaluate caprock sealing after injection according to the actual injection conditions.

\section{Conclusions}

This paper investigated the influence of confining pressure on mechanics-permeability behavior of Yingcheng mudstone based on true triaxial compressive experiments. The pore pressure and deviatoric stress in the $\sigma_{2}$ direction for all specimens are set to $5 \mathrm{MPa}$ and $2 \mathrm{MPa}$, respectively. Several main conclusions can be drawn as follows:

(1) The sensitivity of the mudstone strength to the confining pressure under low confining pressure is higher than that under high confining pressure, and the relationship between strength and confining pressure can be represented by a bilinear model

(2) As the confining pressure increases, the fractural angle, i.e., the angle between the normal of the fault and the $\sigma_{1}$ direction, is smaller and the fault is flatter

(3) Increased confining pressure can greatly improve the ductility of mudstone; the failure mode of mudstone transforms from brittle to ductile under an effective confining pressure of $35 \mathrm{MPa}$

(4) Mudstone permeability is reduced by approximately 5 times under hydrostatic pressure when the effective confining pressure is increased from 3 to $45 \mathrm{MPa}$

(5) Mudstone permeability under deviatoric compression before failure first decreases and then increases as a result of the combination of compaction and dilatancy induced by the evolution of microcracks. The strain corresponding to the turning point of permeability is between the strains corresponding to the onset of dilatancy and the turning point of volumetric strain

(6) A strain-based permeability evolution predictive model, whose prediction is consistent with the experimental data, is proposed with two variables of strain in the $\sigma_{1}$ direction and tangent Poisson's ratio to reflect the effects of compaction and dilatancy on permeability, respectively

(7) The jump in mudstone permeability induced by fault formation decreases exponentially with an increase in confining pressure; when the effective confining pressure reaches $25 \mathrm{MPa}$, the change in permeability caused by the fault is negligible

In summary, the increase in confining pressure has great advantages for the sealing performance of mudstone: it improves the strength and ductility of mudstone while effectively reducing permeability, especially after the peak.

\section{Data Availability}

(1) The experimental data used to analyze the strength and deformation behavior of mudstone (Figures 3-7 and 9) in this study are included within the supplementary information files (Deviatoric_stress_vs_epsilon1.xlsx, Deviatoric_stress_ vs_epsilon1.xlsx, and Deviatoric_stress_vs_epsilon1.xlsx). (2) The experimental data used to analyze the permeability evolution (Figures 8 and 10) in this study are included within the supplementary information file (Permeability vs_epsilon1).

\section{Conflicts of Interest}

The authors declare that there are no conflicts of interest regarding the publication of this article.

\section{Acknowledgments}

This research is supported by the National Key Research and Development Program of China (No. 2018YFB0605601) and the General Program of the National Natural Science Foundation of China (No. 41472236).

\section{Supplementary Materials}

The supplementary material contains four data tables: Tables S1 to S3 are the original data corresponding to Figures 1-3 that plot the relationships between the deviatoric stress and the three strains, respectively; Table S4 shows the data of permeability and corresponding strain $\epsilon_{1}$. (Supplementary Materials)

\section{References}

[1] G. M. Ingram and J. L. Urai, "Top-seal leakage through faults and fractures: the role of mudrock properties," Geological Society of London, Special Publication, vol. 158, no. 1, pp. 125-135, 1999.

[2] R. E. McKernan, E. H. Rutter, J. Mecklenburgh, K. G. Taylor, and S. J. Covey-Crump, "Influence of effective pressure on mudstone matrix permeability: implications for shale gas production," in SPE/EAGE European Unconventional Resources Conference and Exhibition, Vienna, Austria, February 2014.

[3] S. Schlömer and B. M. Krooss, "Experimental characterisation of the hydrocarbon sealing efficiency of cap rocks," Marine and Petroleum Geology, vol. 14, no. 5, pp. 565-580, 1997. 
[4] Y. Yang and A. C. Aplin, "Permeability and petrophysical properties of 30 natural mudstones," Journal of Geophysical Research - Solid Earth, vol. 112, no. B3, article B03206, 2007.

[5] J. Billiotte, D. Yang, and K. Su, "Experimental study on gas permeability of mudstones," Physics and Chemistry of the Earth, vol. 33, pp. S231-S236, 2008.

[6] H. Daigle and B. Dugan, "An improved technique for computing permeability from NMR measurements in mudstones," Journal of Geophysical Research - Solid Earth, vol. 116, no. B8, pp. 1-14, 2011.

[7] P. J. Armitage, R. H. Worden, D. R. Faulkner, A. R. Butcher, and A. A. Espie, "Permeability of the Mercia Mudstone: suitability as caprock to carbon capture and storage sites," Geofluids, vol. 16, no. 1, 42 pages, 2016.

[8] N. Zhang, F. Zhao, P. Guo et al., "Nanoscale pore structure characterization and permeability of mudrocks and finegrained sandstones in coal reservoirs by scanning electron microscopy, mercury intrusion porosimetry, and low-field nuclear magnetic resonance," Geofluids, vol. 2018, Article ID 2905141, 20 pages, 2018.

[9] J. F. Harrington, C. C. Graham, E. Tamayo-Mas, and D. Parkes, "Stress controls on transport properties of the Mercia Mudstone Group: importance for hydrocarbon depletion and $\mathrm{CO}_{2}$ injection," Marine and Petroleum Geology, vol. 93, pp. 391-408, 2018.

[10] Y. Yang and A. C. Aplin, "Influence of lithology and compaction on the pore size distribution and modelled permeability of some mudstones from the Norwegian margin," Marine and Petroleum Geology, vol. 15, no. 2, pp. 163-175, 1998.

[11] A. Hildenbrand and J. L. Urai, "Investigation of the morphology of pore space in mudstones-first results," Marine and Petroleum Geology, vol. 20, no. 10, pp. 1185-1200, 2003.

[12] P. M. Doyen, "Permeability, conductivity, and pore geometry of sandstone," Journal of Geophysical Research, vol. 93, no. B7, pp. 7729-7740, 1988.

[13] G. S. Padhy, C. Lemaire, E. S. Amirtharaj, and M. A. Ioannidis, "Pore size distribution in multiscale porous media as revealed by DDIF-NMR, mercury porosimetry and statistical image analysis," Colloids and Surfaces A: Physicochemical and Engineering Aspects, vol. 300, no. 1-2, pp. 222-234, 2007.

[14] C. E. Neuzil, "How permeable are clays and shales?," Water Resources Research, vol. 30, no. 2, pp. 145-150, 1994.

[15] Y. Yang and A. C. Aplin, "Definition and practical application of mudstone porosity-effective stress relationships," Petroleum Geoscience, vol. 10, no. 2, pp. 153-162, 2004.

[16] Y. Yang and A. C. Aplin, "A permeability-porosity relationship for mudstones," Marine and Petroleum Geology, vol. 27, no. 8, pp. 1692-1697, 2010.

[17] J. Schneider, P. B. Flemings, R. J. Day-Stirrat, and J. T. Germaine, "Insights into pore-scale controls on mudstone permeability through resedimentation experiments," Geology, vol. 39, no. 11, pp. 1011-1014, 2011.

[18] J. S. Reece, P. B. Flemings, B. Dugan, H. Long, and J. T. Germaine, "Permeability-porosity relationships of shallow mudstones in the Ursa Basin, northern deepwater Gulf of Mexico," Journal of Geophysical Research - Solid Earth, vol. 117, no. B12, article B12102, 2012.

[19] D. N. Dewhurst, Y. Yang, and A. C. Aplin, "Permeability and fluid flow in natural mudstones," Geological Society of London, Special Publication, vol. 158, no. 1, pp. 23-43, 1999.
[20] N. H. Mondol, K. Bjorlykke, and J. Jahren, "Experimental compaction of clays: relationship between permeability and petrophysical properties in mudstones," Petroleum Geoscience, vol. 14, no. 4, pp. 319-337, 2008.

[21] Z. Zeng, X. Li, L. Shi, B. Bai, Z. Fang, and Y. Wang, "Experimental study of the laws between the effective confining pressure and mudstone permeability," Energy Procedia, vol. 63, pp. 5654-5663, 2014.

[22] T. A. Torp and J. Gale, "Demonstrating storage of $\mathrm{CO}_{2}$ in geological reservoirs: the Sleipner and SACS projects," Energy, vol. 29, no. 9-10, pp. 1361-1369, 2004.

[23] J. Underschultz, C. Boreham, T. Dance et al., " $\mathrm{CO}_{2}$ storage in a depleted gas field: an overview of the CO2CRC Otway Project and initial results," International Journal of Greenhouse Gas Control, vol. 5, no. 4, pp. 922-932, 2011.

[24] J. Rutqvist, "The geomechanics of $\mathrm{CO}_{2}$ storage in deep sedimentary formations," Geotechnical and Geological Engineering, vol. 30, no. 3, pp. 525-551, 2012.

[25] X. Wu, "Shenhua Group's carbon capture and storage (CCS) demonstration," Mining Report, vol. 150, no. 1-2, pp. 81-84, 2014.

[26] S. Li, Y. Li, Y. Li, Z. Wu, and G. Zhou, "Permeability-strain equations corresponding to the complete stress-strain path of Yinzhuang sandstone," International Journal of Rock Mechanics and Mining Sciences, vol. 31, no. 4, pp. 383-391, 1994.

[27] X. Li, "Permeability change in sandstones under compressive stress condition," $\mathrm{PhD}$ Thesis, Ibaraki University, Ibaraki, 2001.

[28] J. A. Wang and H. D. Park, "Fluid permeability of sedimentary rocks in a complete stress-strain process," Engineering Geology, vol. 63, no. 3-4, pp. 291-300, 2002.

[29] J. Heiland, "Laboratory testing of coupled hydro-mechanical processes during rock deformation," Hydrogeology Journal, vol. 11, no. 1, pp. 122-141, 2003.

[30] X. Li, M. Takahashi, Z. Wu, H. Koide, and T. Ohsumi, "Faulting-induced permeability change in Shirahama sandstone and implication for $\mathrm{CO}_{2}$ aquifer storage," Chinese Journal of Rock Mechanics and Engineering, vol. 22, pp. 9951001, 2003.

[31] T. H. Yang, J. Liu, W. C. Zhu, D. Elsworth, L. G. Tham, and C. A. Tang, "A coupled flow-stress-damage model for groundwater outbursts from an underlying aquifer into mining excavations," International Journal of Rock Mechanics and Mining Sciences, vol. 44, no. 1, pp. 87-97, 2007.

[32] D. W. Hu, H. Zhou, F. Zhang, and J. F. Shao, "Evolution of poroelastic properties and permeability in damaged sandstone," International Journal of Rock Mechanics and Mining Sciences, vol. 47, no. 6, pp. 962-973, 2010.

[33] R. Zhang, Z. Jiang, Q. Sun, and S. Zhu, "The relationship between the deformation mechanism and permeability on brittle rock," Natural Hazards, vol. 66, no. 2, pp. 1179-1187, 2013.

[34] M. D. Zoback and J. D. Byerlee, "The effect of microcrack dilatancy on the permeability of Westerly granite," Journal of Geophysical Research, vol. 80, no. 5, pp. 752-755, 1975.

[35] M. Souley, F. Homand, S. Pepa, and D. Hoxha, "Damageinduced permeability changes in granite: a case example at the URL in Canada," International Journal of Rock Mechanics and Mining Sciences, vol. 38, no. 2, pp. 297-310, 2001.

[36] L. Chen, J. F. Liu, C. P. Wang, J. Liu, R. Su, and J. Wang, "Characterization of damage evolution in granite under 
compressive stress condition and its effect on permeability," International Journal of Rock Mechanics and Mining Sciences, vol. 71, pp. 340-349, 2014.

[37] L. Wang, J. Liu, J. Pei, H. Xu, and Y. Bian, "Mechanical and permeability characteristics of rock under hydro-mechanical coupling conditions," Environment and Earth Science, vol. 73, no. 10, pp. 5987-5996, 2015.

[38] Y. Zhao, J. Tang, Y. Chen et al., "Hydromechanical coupling tests for mechanical and permeability characteristics of fractured limestone in complete stress-strain process," Environment and Earth Science, vol. 76, no. 1, p. 24, 2017.

[39] S. Uehara and M. Takahashi, "Evolution of permeability and microstructure of experimentally-created shear zones in Neogene siliceous mudstones from Horonobe, Japan," Journal of Structural Geology, vol. 60, pp. 46-54, 2014.

[40] C. L. Zhang, "The stress-strain-permeability behaviour of clay rock during damage and recompaction," Journal of Rock Mechanics and Geotechnical Engineering, vol. 8, no. 1, pp. 16-26, 2016.

[41] L. Shi, Z. Zeng, B. Bai, and X. Li, "Effect of the intermediate principal stress on the evolution of mudstone permeability under true triaxial compression," Greenhouse Gases: Science and Technology, vol. 8, no. 1, pp. 37-50, 2018.

[42] L. Shi, X. Li, B. Bing, A. Wang, Z. Zeng, and H. He, “A Mogi-type true triaxial testing apparatus for rocks with two moveable frames in horizontal layout for providing orthogonal loads," Geotechnical Testing Journal, vol. 40, no. 4, pp. 20160242-20160558, 2017.

[43] S. Hu, X. Li, B. Bai, L. Shi, M. Liu, and H. Wu, "A modified true triaxial apparatus for measuring mechanical properties of sandstone coupled with $\mathrm{CO}_{2}-\mathrm{H}_{2} \mathrm{O}$ biphase fluid," Greenhouse Gases: Science and Technology, vol. 7, no. 1, pp. 78-91, 2017.

[44] S. Hu, X. Li, and B. Bai, "Effects of different fluids on microcrack propagation in sandstone under true triaxial loading conditions," Greenhouse Gases: Science and Technology, vol. 8, no. 2, pp. 349-365, 2018.

[45] Q. Zhang, X. Li, B. Bai, S. Hu, and L. Shi, "Effect of pore fluid pressure on the normal deformation of a matched granite joint," Processes, vol. 6, no. 8, p. 107, 2018.

[46] B. Haimson and C. Chang, "A new true triaxial cell for testing mechanical properties of rock, and its use to determine rock strength and deformability of Westerly granite," International Journal of Rock Mechanics and Mining Sciences, vol. 37, no. 1-2, pp. 285-296, 2000.

[47] K. Mogi, Experimental Rock Mechanics, Taylor \& Francis, Leiden, AK, 2007.

[48] X. T. Feng, X. Zhang, R. Kong, and G. Wang, "A novel Mogi type true triaxial testing apparatus and its use to obtain complete stress-strain curves of hard rocks," Rock Mechanics and Rock Engineering, vol. 49, no. 5, pp. 16491662, 2016.

[49] X. Chen, J. Yu, C. Tang, H. Li, and S. Wang, "Experimental and numerical investigation of permeability evolution with damage of sandstone under triaxial compression," Rock Mechanics and Rock Engineering, vol. 50, no. 6, pp. 15291549, 2017.

[50] W. F. Brace, J. B. Walsh, and W. T. Frangos, "Permeability of granite under high pressure," Journal of Geophysical Research, vol. 73, no. 6, pp. 2225-2236, 1968.

[51] X. Li, Y. Wang, and N. Wei, "Research on measuring method of permeability by using storage-variable transient pulus method," Chinese Journal of Rock Mechanics and Engineering, vol. 27, pp. 2482-2487, 2008.

[52] Y. Wang, X. Li, and N. Wei, "Experimental study of storagevariable transient pulse method for permeability measurement," Chinese Journal of Rock Mechanics and Engineering, vol. 29, pp. 3113-3121, 2010.

[53] S. C. Jones, "A technique for faster pulse-decay permeability measurements in tight rocks," SPE Formation Evaluation, vol. 12, no. 1, pp. 19-26, 1997.

[54] W. Liu, Y. Li, C. Yang, J. J. K. Daemen, Y. Yang, and G. Zhang, "Permeability characteristics of mudstone cap rock and interlayers in bedded salt formations and tightness assessment for underground gas storage caverns," Engineering Geology, vol. 193, pp. 212-223, 2015.

[55] C. David, T. F. Wong, W. Zhu, and J. Zhang, "Laboratory measurement of compaction-induced permeability change in porous rocks: implications for the generation and maintenance of pore pressure excess in the crust," Pure and Applied Geophysics, vol. 143, no. 1-3, pp. 425-456, 1994.

[56] K. Mogi, "Fracture and flow of rocks," Tectonophysics, vol. 13, no. 1-4, pp. 541-568, 1972.

[57] M. You, "Strength criterion for rocks under compressivetensile stresses and its application," Journal of Rock Mechanics and Geotechnical Engineering, vol. 7, no. 4, pp. 434-439, 2015.

[58] H. C. Heard, "Chapter 7: transition from brittle fracture to ductile flow in Solenhofen limestone as a function of temperature, confining pressure, and interstitial fluid pressure," Memoir - Geological Society of America, vol. 79, pp. 193226, 1960.

[59] C. A. Tang, L. G. Tham, P. K. K. Lee, T. H. Yang, and L. C. Li, "Coupled analysis of flow, stress and damage (FSD) in rock failure," International Journal of Rock Mechanics and Mining Sciences, vol. 39, no. 4, pp. 477-489, 2002.

[60] V. Lyakhovsky and Y. Hamiel, "Damage evolution and fluid flow in poroelastic rock," Izvestiya Physics of the Solid Earth, vol. 43, no. 1, pp. 13-23, 2007.

[61] J. Ma, "Review of permeability evolution model for fractured porous media," Journal of Rock Mechanics and Geotechnical Engineering, vol. 7, no. 3, pp. 351-357, 2015.

[62] J. B. Walsh, "The effect of cracks on the compressibility of rock," Journal of Geophysical Research, vol. 70, no. 2, pp. 381-389, 1965.

[63] Z. Zeng, X. Li, L. Shi, and B. Bai, “Testing study on variational characteristics of the permeability for mudstone and sandstone with the change of confining pressure," Journal of Transport Science and Engineering, vol. 31, pp. 1-5, 2015.

[64] J. Zhang, T.-F. Wong, and D. M. Davis, "Micromechanics of pressure-induced grain crushing in porous rocks," Journal of Geophysical Research, vol. 95, no. B1, p. 341, 1990.

[65] L. S. Costin, "A microcrack model for the deformation and failure of brittle rock," Journal of Geophysical Research - Solid Earth, vol. 88, no. B11, pp. 9485-9492, 1983.

[66] J. M. Kemeny, "A model for non-linear rock deformation under compression due to sub-critical crack growth," International Journal of Rock Mechanics and Mining Science and Geomechanics Abstracts, vol. 28, no. 6, pp. 459-467, 1991.

[67] Z. Jin, Y. Yuan, D. Sun, Q. Liu, and S. Li, "Models for dynamic evaluation of mudstone/shale cap rocks and their applications in the Lower Paleozoic sequences, Sichuan Basin, SW China," Marine and Petroleum Geology, vol. 49, pp. 121-128, 2014. 
[68] L. H. Chen, H. Y. Li, and X. J. Hua, The Assessment of the Source-Reservoir-Cap Rock, Petroleum Industry Press, Beijing, China, 1999.

[69] H. Wu, B. Bai, and X. Li, “An advanced analytical solution for pressure build-up during $\mathrm{CO}_{2}$ injection into infinite saline aquifers: the role of compressibility," Advances in Water Resources, vol. 112, pp. 95-105, 2018.

[70] J. Rutqvist, "Status of the TOUGH-FLAC simulator and recent applications related to coupled fluid flow and crustal deformations," Computational Geosciences, vol. 37, no. 6, pp. 739-750, 2011.

[71] R. Nygård, M. Gutierrez, R. K. Bratli, and K. Høeg, "Brittleductile transition, shear failure and leakage in shales and mudrocks," Marine and Petroleum Geology, vol. 23, no. 2, pp. 201-212, 2006. 

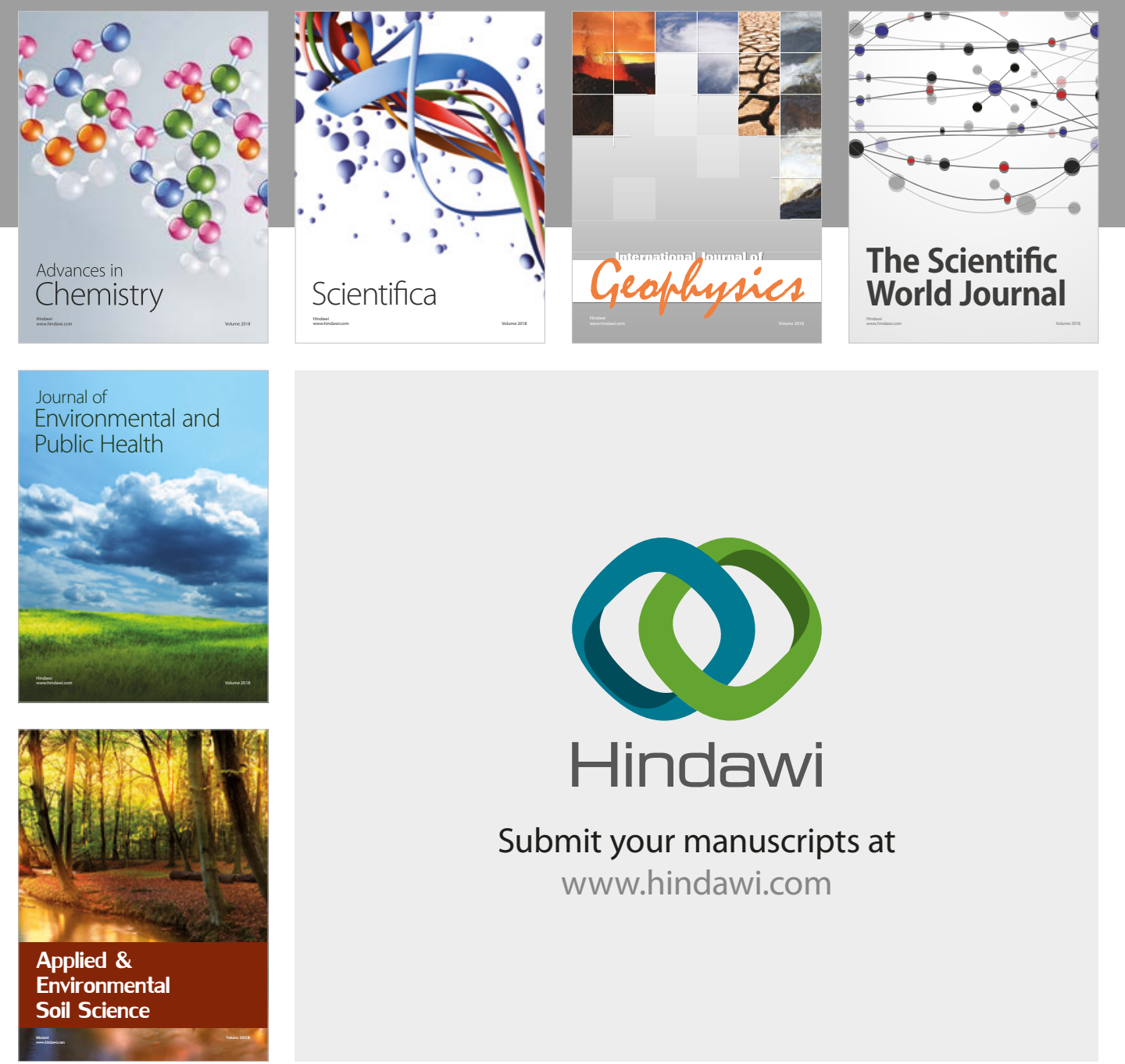

The Scientific

\section{World Journal}
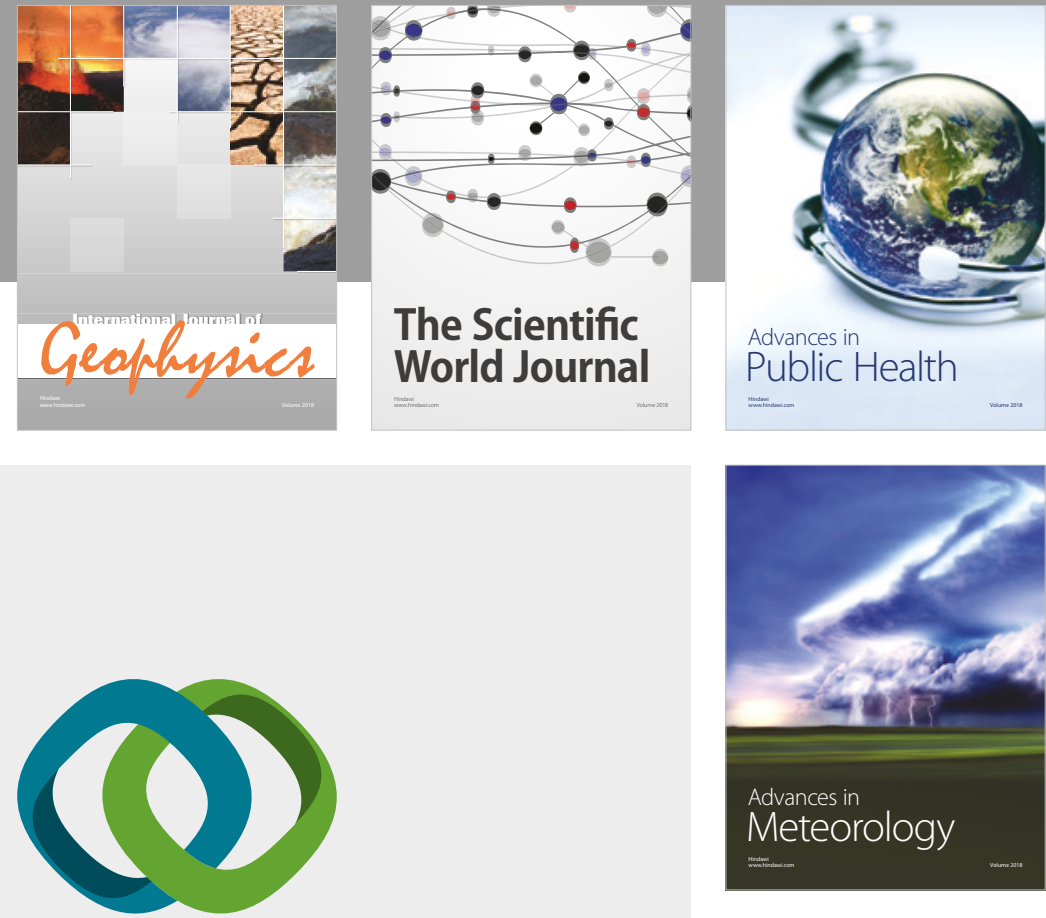

Advan

Public Health

\section{Hindawi}

Submit your manuscripts at

www.hindawi.com
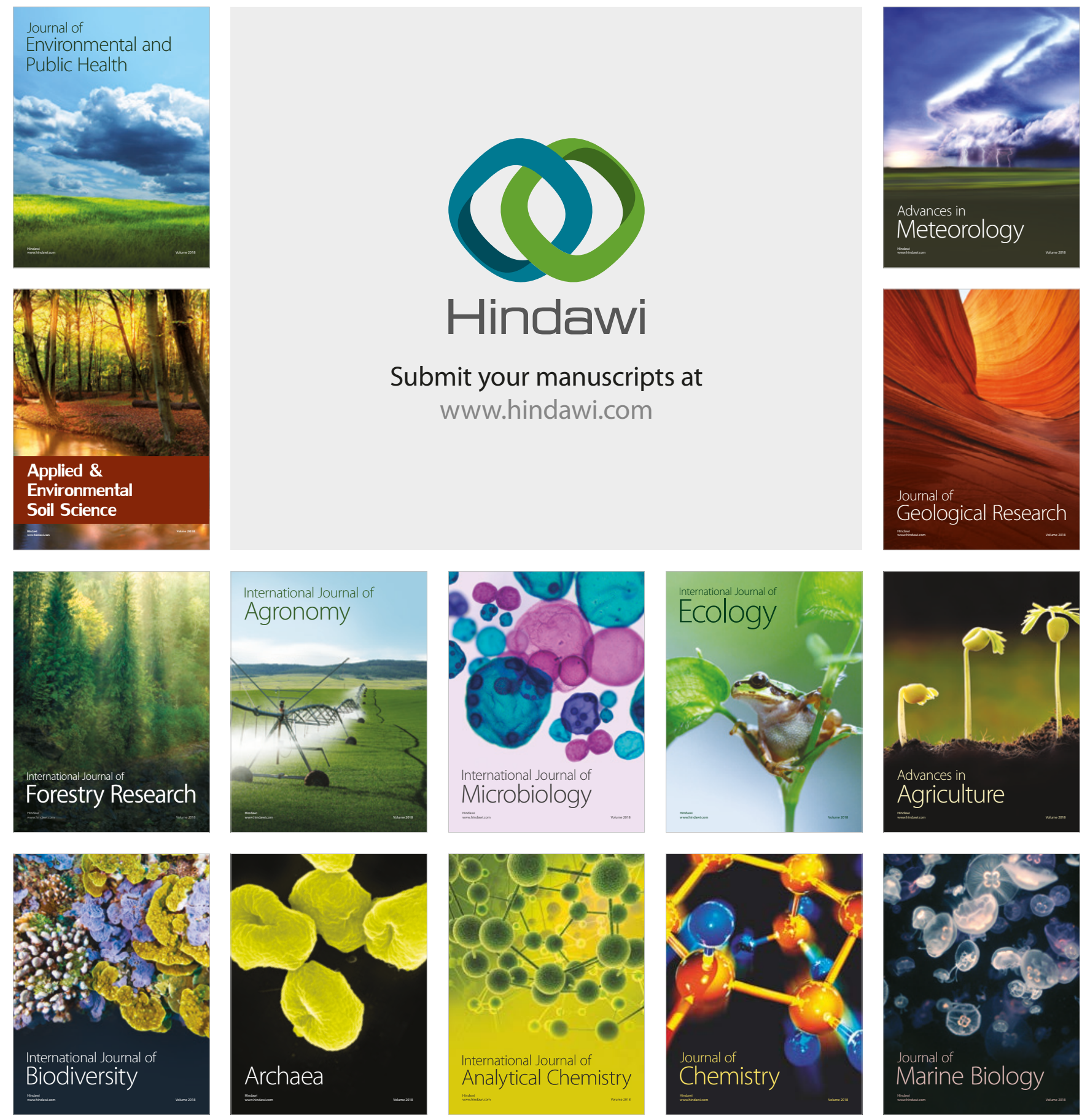